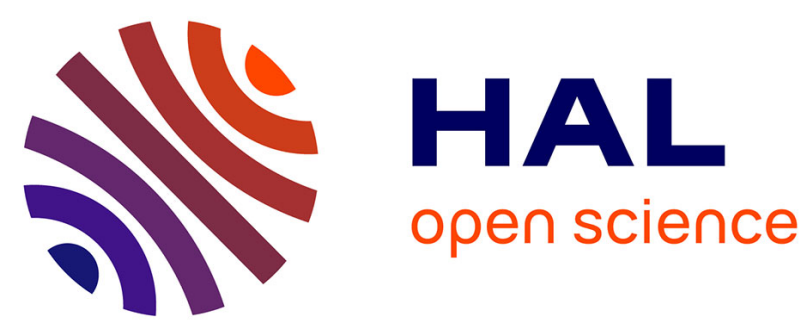

\title{
Magnetic properties and synthesis conditions of Nd2Fe23B3 melt-spun alloy
}

Hervé Mayot, Olivier Isnard, Jean-Louis Soubeyroux

\section{To cite this version:}

Hervé Mayot, Olivier Isnard, Jean-Louis Soubeyroux. Magnetic properties and synthesis conditions of Nd2Fe23B3 melt-spun alloy. Journal of Magnetism and Magnetic Materials, 2007, 316, pp.e477-e480. 10.1016/j.jmmm.2007.02.189 . hal-00264974

\section{HAL Id: hal-00264974 https://hal.science/hal-00264974}

Submitted on 18 Mar 2008

HAL is a multi-disciplinary open access archive for the deposit and dissemination of scientific research documents, whether they are published or not. The documents may come from teaching and research institutions in France or abroad, or from public or private research centers.
L'archive ouverte pluridisciplinaire HAL, est destinée au dépôt et à la diffusion de documents scientifiques de niveau recherche, publiés ou non, émanant des établissements d'enseignement et de recherche français ou étrangers, des laboratoires publics ou privés. 


\title{
Magnetic properties and synthesis conditions of $\mathrm{Nd}_{2} \mathrm{Fe}_{23} \mathrm{~B}_{3}$ melt-spun alloy
}

\author{
H. Mayot ${ }^{\mathrm{a}, *}$, O. Isnard ${ }^{\mathrm{a}}$, J.-L. Soubeyroux ${ }^{\mathrm{a}}$ \\ ${ }^{a}$ Laboratoire de Cristallographie, CNRS Université J. Fourier, BP 166, 38042 Grenoble Cedex 9, France
}

Elsevier use only: Received date here; revised date here; accepted date here

\begin{abstract}
The formation of amorphous and crystalline state of the $\mathrm{Nd}_{2} \mathrm{Fe}_{23} \mathrm{~B}_{3}$ alloy from melt-spun ribbon is presented. The synthesis conditions are investigated combining DSC, X-ray diffraction and thermomagnetic analysis. The thermomagnetic analysis is found to be very useful to optimize the synthesis process. Comparison of these results enables to discuss the thermal stability of both the amorphous and crystalline phases. It is found that the onset temperature of the $\alpha$-iron formation is significantly smaller than $\operatorname{the~} \mathrm{Nd}_{2} \mathrm{Fe}_{23} \mathrm{~B}_{3}$ crystallization temperature. Magnetization measurements have also been carried out on the as spun ribbon and the crystalline $\mathrm{Nd}_{2} \mathrm{Fe}_{23} \mathrm{~B}_{3}$ sample. The crystalline phase is found to exhibit a much larger Curie temperature than the amorphous one as well as a larger saturation magnetization.
\end{abstract}

PACS: 75.30.-m; 75.50.Kj; 75.50.Ww; 75.20.En

Keywords: amorphous magnetic material; metastable intermetallic phase; hard magnetic materials;

\section{Introduction}

Due to their magnetic properties and their possible applications, intermetallic $\mathrm{R}-\mathrm{T}-\mathrm{X}(\mathrm{R}=$ rare earth, $\mathrm{T}=\mathrm{Fe}$ or $\mathrm{Co}$ and $\mathrm{X}$ is a metalloid) compounds have been the subjects of many studies to determine their phase diagrams and the properties of each phase. Since the discovery of the $\mathrm{Nd}_{2} \mathrm{Fe}_{14} \mathrm{~B}$ type, high performance magnets the $\mathrm{Nd}-\mathrm{Fe}-\mathrm{B}$ ternary phase diagram has been intensively studied. Several phases have been discovered among which $\mathrm{Nd}_{2} \mathrm{Fe}_{23} \mathrm{~B}_{3}$ is one of the latest found $[1,2]$. It is not found in classical melting but crystallize in melt spun amorphous alloy upon annealing and the $\mathrm{Nd}_{2} \mathrm{Fe}_{23} \mathrm{~B}_{3}$ is thus considered as a metastable phase[1-4].

Here we present an investigation of the $\mathrm{Nd}_{2} \mathrm{Fe}_{23} \mathrm{~B}_{3}$ crystalline phase formation by combining $\mathrm{x}$-ray diffraction and magnetic measurements as well as a determination of its magnetic properties.

\section{Experimental}

An alloy of composition $\mathrm{Nd}_{2} \mathrm{Fe}_{23} \mathrm{~B}_{3}$ has been prepared from elements of purity better than 99,95\%. The stoechiometric amount of the elements has been melted using first an arc furnace and then a HF induction furnace to ensure better homogeneity. Then, ribbons have been obtained from the ingot by means of standard melt spinning under purified argon atmosphere. The copper wheel of the melt spinning device had a diameter of $200 \mathrm{~mm}$ and spun at a speed of $2000 \mathrm{rev} . / \mathrm{min}$ corresponding to a surface speed of $21 \mathrm{~m} / \mathrm{s}$ and leading to 30 to $55 \mu \mathrm{m}$ thick ribbons.

The X-ray diffraction investigations have been carried out using $C u_{K_{\alpha}}$ radiations either in reflection geometry on ribbons or in transmission geometry in case of powders.

Differential scanning calorimetry (DSC) has been performed using different heating rates from 5 to $20 \mathrm{~K} / \mathrm{min}$. The temperature dependence of the magnetization has been measured on a Faraday-type balance. Many different heat treatments were used during such measurements. Heating rates ranged from 5 to $20 \mathrm{~K} / \mathrm{min}$ and the maximum temperatures used were between $778 \mathrm{~K}$ (slightly above Curie temperatures)

* Corresponding author. Tel.: +33-4-76887403; fax: +33-4-76881038.

E-mail address: herve.mayot@grenoble.cnrs.fr 


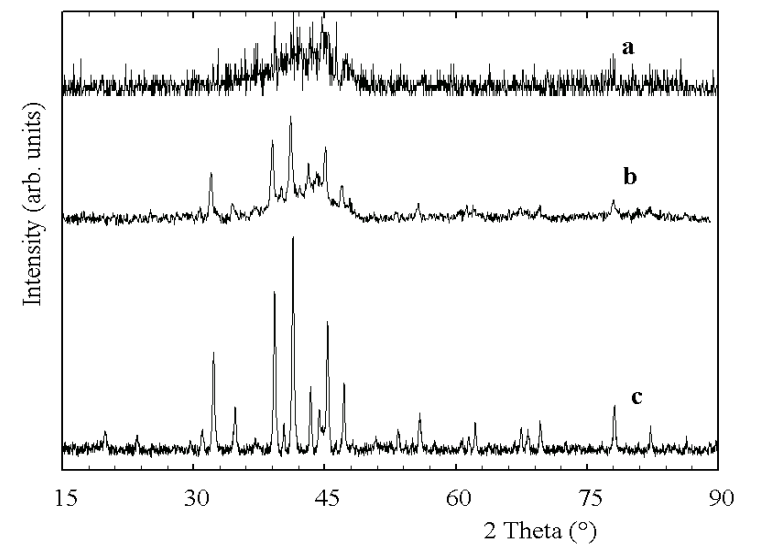

Fig. 1. $\mathrm{X}$ ray diffraction on $\mathrm{Nd}_{2} \mathrm{Fe}_{23} \mathrm{~B}_{3}$ : a) reflection geometry on amorphous ribbon (wheel side); b) transmission geometry on powder before annealing; c) same as b) after annealing.

and $1150 \mathrm{~K}$. The Curie temperatures of both amorphous and crystalline phases have been measured from those thermomagnetic measurements whereas the crystallization temperatures were deduced from the analysis of both DSC and thermomagnetic investigations.

Both melt spun and annealed samples were studied by means of magnetic measurement at temperatures ranging from 4 to $300 \mathrm{~K}$ and magnetic fields up to $10 \mathrm{~T}$ using the extraction method.

\section{Results}

\subsection{X-ray diffraction}

X-ray diffraction performed in reflection geometry on meltspun ribbons reveals that the surface of the ribbon that was on contact with the wheel is amorphous at least in the depth probed by the X-rays. Indeed, a broad intensity maximum characteristic of amorphous alloys is observed on figure 1.a. However, once the sample is reduced into powder, X-ray diffraction clearly shows that the volume of the ribbons, which was frozen more slowly, is partially crystallized (see figure 1.b). The crystalline phase however corresponds to $\mathrm{Nd}_{2} \mathrm{Fe}_{23} \mathrm{~B}_{3}$ compound reported previously [1]. Even if the surface speed of the wheel was not enough to obtain a totally amorphous alloy, it was however sufficient to avoid the formation of high temperature stable phases like $\mathrm{Nd}_{2} \mathrm{Fe}_{14} \mathrm{~B}$ or $\mathrm{Nd}_{1.11} \mathrm{Fe}_{4} \mathrm{~B}_{4}$.

After vacuum annealing for $10 \mathrm{~min}$. at $628{ }^{\circ} \mathrm{C}$, the diffraction pattern (see figure 1.c) does not show any broad amorphous peak anymore and seems to fully correspond to pure $\mathrm{Nd}_{2} \mathrm{Fe}_{23} \mathrm{~B}_{3}$ pattern. Indeed all the observed Bragg reflections have been indexed using the cubic $I \overline{4} 3 d$ space group (No. 220). The unit cell has a lattice parameter of $14.160 \AA$ contains 8 formula units leading to 224 atoms per cell [1].

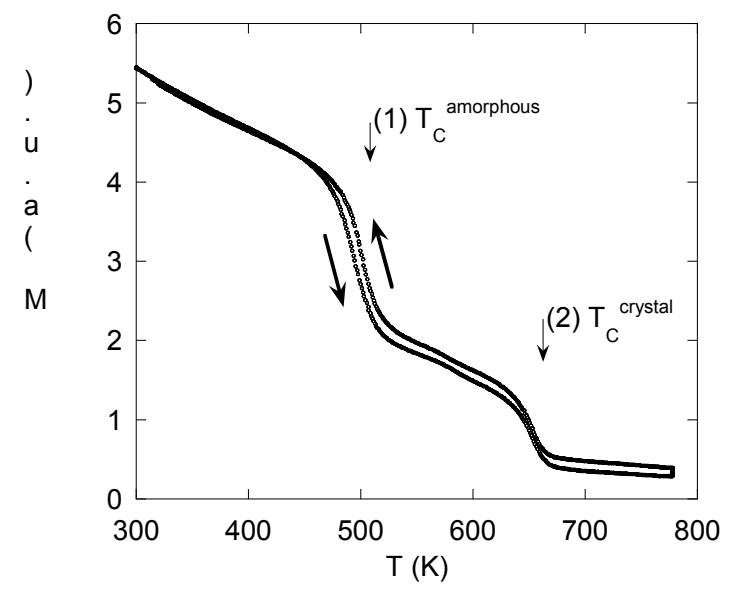

Fig. 2. Thermomagnetic measurement up to $778 \mathrm{~K}$. Arrows indicate portion of curve measured when heating and when cooling.

\subsection{Differential scanning calorimetry and thermomagnetic analysis}

DSC measurements show an exothermic peak centered around $625^{\circ} \mathrm{C}$ which corresponds to the crystallization temperature. Our measurements present a broader peak than those of reference [2]. This is probably due to less homogeneous melt spun ribbons, since our sample contains noticeable amount of crystalline phase, which may favor the crystallization.

Examples of the thermomagnetic measurements performed on melt-spun samples are shown on Figure 2 and 3. In figure 2 , the sample has been heated up to $778 \mathrm{~K}$, kept at this temperature for $1 \mathrm{~h}$ and then cooled down to room temperature. Upon heating two Curie temperature are observed: $\mathrm{T}_{\mathrm{C}}=517$ and $660 \mathrm{~K}$ which correspond to the $\mathrm{Nd}_{2} \mathrm{Fe}_{23} \mathrm{~B}_{3}$ amorphous alloy and crystallized compound respectively. These values are in good agreement with earlier published values $[1,2]$. Figure 2 clearly shows an increase of the magnetic signal during the isotherm at $778 \mathrm{~K}$. This increase is not due to the crystallization of the phase. The temperature of the isotherm is higher than both Curie temperatures. At this temperature the magnetic signal coming from either the amorphous or the crystalline phase are negligible since they both are in the paramagnetic state. Moreover, the jump of the magnetic signal at $\mathrm{T}_{(2)}\left(\mathrm{T}_{\mathrm{C}}\right.$ of crystalline phase) has the same magnitude upon heating or cooling. This proves that the quantity of crystalline phase did not increase. On the other hand the amorphous phase quantity seems to be reduced since the corresponding magnetization step is smaller upon cooling. X-Ray diffraction performed on the sample after the thermomagnetic cycle of figure 2, shows clearly an additional peak, which correspond to the main peak of the $\alpha$-Fe phase. Since the $\alpha$-Fe Curie temperature is effectively higher than isotherm temperature $778 \mathrm{~K}$, the increase of the magnetic signal occurring during the isothermal treatment at $778 \mathrm{~K}$ corresponds to the $\alpha-\mathrm{Fe}$ formation. It is worth to note that the $\alpha$-Fe crystallized from the amorphous phase whose quantity has been reduced, reaction that occurs at temperature lower than the 


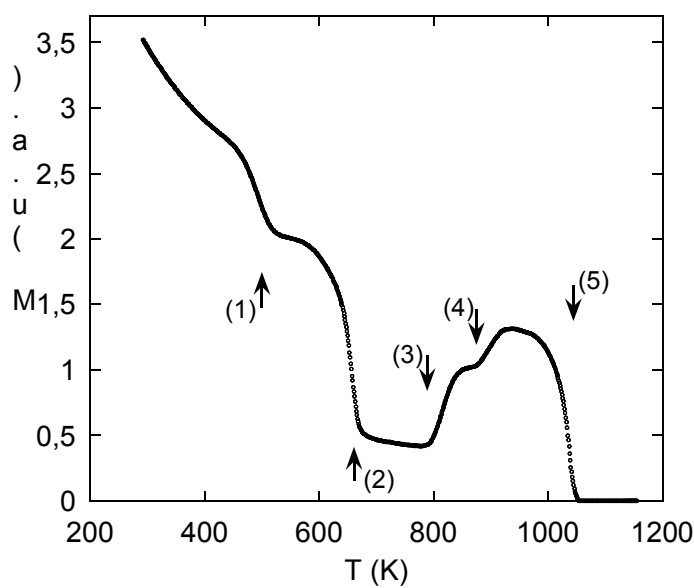

Fig. 3. Thermomagnetic measurement upon heating at $10 \mathrm{~K} / \mathrm{min}$. The numbers indicating specific temperatures are discussed in text.

crystallization of the $\mathrm{Nd}_{2} \mathrm{Fe}_{23} \mathrm{~B}_{3}$ from the amorphous alloy (crystallization temperature of $898 \mathrm{~K}$ ). This result confirms the metastable character of the crystalline $\mathrm{Nd}_{2} \mathrm{Fe}_{23} \mathrm{~B}_{3}$ phase and shows that $\alpha$-Fe formation occurs during the isotherm.

A thermomagnetic investigation carried out up to $1150 \mathrm{~K}$ is displayed in Figure 3. The plot exhibits many different magnetic transitions among which one can recognize $T_{(1)}$ and $T_{(2)}$, the $T_{C}$ of the amorphous alloy and the crystalline phase respectively. At higher temperature we see the bump due to $\alpha$-Fe formation from about $800 \mathrm{~K}\left(\mathrm{~T}_{(3)}\right)$ to $1043 \mathrm{~K}\left(\mathrm{~T}_{(5)}\right)$. This later temperature corresponds to the Curie temperature of $\alpha$ Fe. The increase of the magnetic signal above $800 \mathrm{~K}$, due to formation of $\alpha$-Fe, occurs in two steps. We have seen that during the first step (at $\mathrm{T}_{(3)}$ ), $\alpha$-Fe crystallizes from the amorphous phase. Using both $\mathrm{x}$-ray diffraction and other thermomagnetic investigations at intermediate temperatures [5] we have determined that the temperature of the second increase $\left(\mathrm{T}_{(4)} \approx 880 \mathrm{~K}\right)$ corresponds to the temperature at which the crystalline $\mathrm{Nd}_{2} \mathrm{Fe}_{23} \mathrm{~B}_{3}$ phase decomposed into $\alpha$-Fe and other stable phases. X-ray patterns show peaks from $\mathrm{Nd}_{2} \mathrm{Fe}_{14} \mathrm{~B}$ and $\mathrm{Nd}_{1.11} \mathrm{Fe}_{4} \mathrm{~B}_{4}$ phases.

\subsection{Magnetization measurements}

If the $\mathrm{Nd}_{2} \mathrm{Fe}_{23} \mathrm{~B}_{3}$ exhibits a ferromagnetic behavior in both the amorphous and the crystalline state, the magnetic measurements presented in figure 4 show that the magnetization of the crystalline phase is a little higher than that of amorphous state. At $4 \mathrm{~K}$, the saturation moments are equal to $51.8 \mu_{\mathrm{B}} /$ f.u. and $54.0 \mu_{\mathrm{B}} /$ f.u for amorphous alloy and crystalline phase respectively. Assuming a $\mathrm{Nd}$ magnetic moment of $3.27 \mu_{\mathrm{B}}$ and a ferromagnetic coupling between $\mathrm{Nd}$ and Fe magnetic moments, a mean Fe moment of $2.06 \mu_{\mathrm{B}}$ is obtained for the crystalline state. Using the same reasoning a value of $1.96 \mu_{\mathrm{B}}$ is obtained for the corresponding amorphous alloy. It is worth mention that as discussed elsewhere [6], the sensitivity of the $\mathrm{Fe}$ magnetic moment to its local atomic environment is a general feature of the R-Fe-X ternary intermetallics. The modification of the magnetization observed here probably reflects the difference in the local atomic

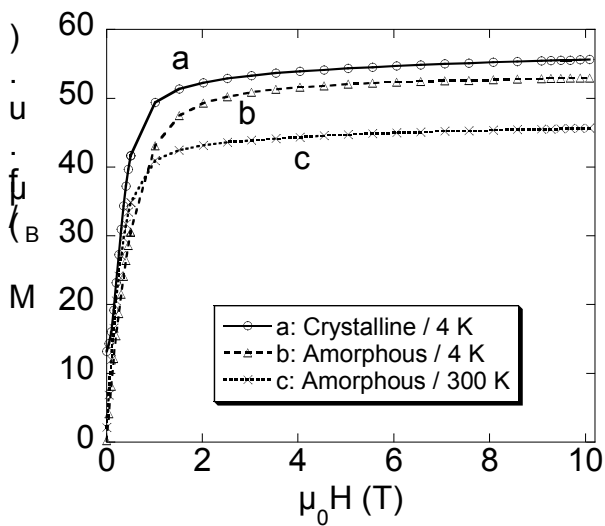

Fig. 4. Magnetisation curves a) on crystallised sample at $4 \mathrm{~K}$, b) on melt spun sample at $4 \mathrm{~K}$ and c) on melt-spun sample at $300 \mathrm{~K}$.

environment of the $\mathrm{Fe}$ atoms in the two different state of the $\mathrm{Nd}_{2} \mathrm{Fe}_{23} \mathrm{~B}_{3}$ alloy: amorphous and crystalline. Due to the large difference in the Curie temperature between the two states of $\mathrm{Nd}_{2} \mathrm{Fe}_{23} \mathrm{~B}_{3}$, one can expect a much smaller magnetization at room temperature for the amorphous alloy. Indeed the saturation magnetizations at $300 \mathrm{~K}$ are $44.5 \mu_{\mathrm{B}} / \mathrm{f}$.u. and 51.7 $\mu_{\mathrm{B}} / \mathrm{f}$.u. for the amorphous alloy and the crystalline compound respectively.

\section{Discussion and conclusion}

It has been found that $\alpha$-Fe impurity cannot be avoided in $\mathrm{Nd}_{2} \mathrm{Fe}_{23} \mathrm{~B}_{3}$ compound when synthesized by annealing of amorphous alloy. This iron formation results primarily from the decomposition of the amorphous $\mathrm{Nd}_{2} \mathrm{Fe}_{23} \mathrm{~B}_{3}$ and occurs even below the crystallization temperature of the $\mathrm{Nd}_{2} \mathrm{Fe}_{23} \mathrm{~B}_{3}$ phase. Thermomagnetic investigations have however shown that, at temperature lower than the crystallization temperature of $\mathrm{Nd}_{2} \mathrm{Fe}_{23} \mathrm{~B}_{3}$, the formation of $\alpha-\mathrm{Fe}$ is rather slow.

Since the kinetic of the $\alpha-\mathrm{Fe}$ formation is slow. Forming the compound as pure as possible is then a question of speed. A good procedure is to anneal the sample at a temperature between 625 and $630{ }^{\circ} \mathrm{C}$ no longer that $10 \mathrm{~min}$. The X-ray pattern obtained after such treatment is plotted in figure 1.c. It shows only the crystalline $\mathrm{Nd}_{2} \mathrm{Fe}_{23} \mathrm{~B}_{3}$ phase (without any broad amorphous peak).

The very short duration of annealing required to crystallize the $\mathrm{Nd}_{2} \mathrm{Fe}_{23} \mathrm{~B}_{3}$ phase indicates that amorphous alloy could have a local scale structure close to the crystal structure. This is consistent with the position on X-ray patterns (see figure 1) of the broad amorphous peak as regard to the main Bragg peaks of the crystal structure.

The larger $\mathrm{T}_{\mathrm{C}}$ of the crystalline state is explained by the increase of magnetization (see figure 4) comparison with the amorphous alloy. The changes of local environments of $\mathrm{Fe}$ atoms across the crystallization can induce noticeable changes of their atomic moments. 


\section{References}

[1] K. H. J. Buschow, et al., J. Less-Common Met. 125 (1986) 135

[2] D. B. De Mooij and K. H. J. Buschow, Philips J. Res 41 (1986) 400

[3] Bao-gen, et al., JMMM 104-107 (1992) 1281

[4] Gou, et al., JMMM 128 (1993) 26

[5] H. Mayot and O. Isnard, in preparation

[6] O. Isnard and D. Fruchart, J. Alloys and Compds 205 (1994) 1 